\title{
Skeletal involvement in Langerhans cell histiocytosis
}

\author{
Suonita Khung • Jean-François Budzik • Elisa Amzallag-Bellenger • \\ Anne Lambilliote • Gustavo Soto Ares • Anne Cotten • \\ Nathalie Boutry
}

Received: 26 April 2013 / Revised: 20 June 2013 / Accepted: 24 June 2013 / Published online: 2 August 2013

(C) The Author(s) 2013. This article is published with open access at Springerlink.com

\begin{abstract}
Langerhans cell histiocytosis (LCH) represents a disorder characterised by an abnormal accumulation of histiocytes in miscellaneous tissues. The bone is commonly affected, especially the flat bones, the spine and the long bones. Some lesions in children such as a "vertebra plana" or a solitary lytic lesion of the skull may be suggestive for $\mathrm{LCH}$, whereas others can be confused with a malignant tumour or osteomyelitis. This pictorial essay presents the main usual and unusual skeletal manifestations observed in LCH.
\end{abstract}

\section{Teaching points}

- Osseous involvement in children with LCH is very similar to that seen in multiple myeloma.

- A solitary lytic lesion of the cranial vault is a typical radiographic finding of $\mathrm{LCH}$.

S. Khung $\cdot$ E. Amzallag-Bellenger $\cdot$ N. Boutry $(\bowtie)$

Department of Pediatric Radiology, Hôpital Jeanne de Flandre,

Université de Lille 2, CHRU de Lille, Lille, France

e-mail: nathalie.boutry@chru-lille.fr

N. Boutry

e-mail: nboutry@gmail.com

S. Khung $\cdot$ A. Cotten

Department of Musculoskeletal Radiology, Hôpital Roger

Salengro, Université de Lille 2, CHRU de Lille, Lille, France

\section{J.-F. Budzik}

Department of Radiology, Hôpital Saint-Philibert, Groupe

Hospitalier de l'Institut Catholique de Lille (GHICL),

Lomme, France

\section{A. Lambilliote}

Department of Pediatric Hematology, Hôpital Jeanne de Flandre,

Université de Lille 2, CHRU de Lille, Lille, France

G. Soto Ares

Department of Neuroradiology, Hôpital Roger Salengro,

Université de Lille 2, CHRU de Lille, Lille, France
- A vertebra plana appearance in the spine is another typical radiographic finding.

- Extensive signal intensity changes within bone marrow on MRI are a helpful sign for the diagnosis.

- In long bones, endosteal scalloping may be responsible for a "budding appearance".

Keywords Langerhans cell histiocytosis - Children . Diagnostic imaging $\cdot$ Radiography $\cdot$ Tomography $\cdot$ Spiral computed $\cdot$ Magnetic resonance imaging

\section{Introduction}

Langerhans cell histiocytosis (LCH) represents a spectrum of rare disorders characterised by idiopathic infiltration and accumulation of abnormal histiocytes (i.e. the Langerhans cells) within various tissues (bone marrow, skin, central nervous system, lung, liver, spleen, lymph nodes) causing focal or systemic effects [1]. LCH predominates in children and its annual incidence is estimated at 4.6 per million in children under 14 years of age [2].

LCH was formerly known as "histiocytosis X", a term that grouped three major syndromes, which are now considered as clinical variants of the same disease: the eosinophilic granuloma (unifocal LCH with a solitary bone lesion), the HandSchüller-Christian disease (multifocal LCH with the classic triad of skull lesions, exophtalmos, and diabetes insipidus) and the Letterer-Siwe disease (fulminant LCH with multiple organ involvement) [3]. The aetiology of LCH remains unknown, and it is still uncertain whether LCH is a neoplastic disorder, suggested by the monoclonality in lesions, or a reactive disorder resulting from a dysregulation of the immune system $[4,5]$.

Clinical presentations of LCH vary widely, from an asymptomatic solitary bone lesion to a multisystem lifethreatening affliction $[1,6,7]$. Any organ or system of the 
human body can be involved, but the skeleton, the skin and the central nervous system are more commonly affected [1, $6,7]$. Biopsy taken from the most easily accessible lesion (usually a skin or a soft tissue biopsy) is necessary to confirm the diagnosis. Histopathological examination shows tissue infiltration by abnormal Langerhans cells as well as normal inflammatory cells ( $\mathrm{T}$ cells, eosinophils, macrophages and multinucleated giant cells) [1]. Diagnosis is confirmed by the morphologic identification of the Langerhans cells and positive immunohistochemical staining with CD1a and/or CD207. The identification of Birbeck granules on electron microscopy, which are cytoplasmic tennis-racket-shaped organelles characteristic of Langerhans cells, is nowadays rarely performed [6]. A bone biopsy is often not needed for the diagnosis of $\mathrm{LCH}$, but it may be required in some cases. When the risk of such a biopsy outweighs the need for a definitive diagnosis (as this may be the case in some children with isolated upper cervical vertebral involvement), careful monitoring by clinical examination and appropriate imaging for at least the next 6 months is necessary in order to exclude a malignancy and to reassess the need for biopsy [7].

Once the diagnosis has been ascertained, the treatment depends on the extent and severity of LCH. Extent of the disease makes the distinction between single system disease
Fig. 1 Low-dose biplanar skeletal survey (anteroposterior view) reveals bone lesions (arrows) of the calvarium, the proximal left humerus and the proximal left femur

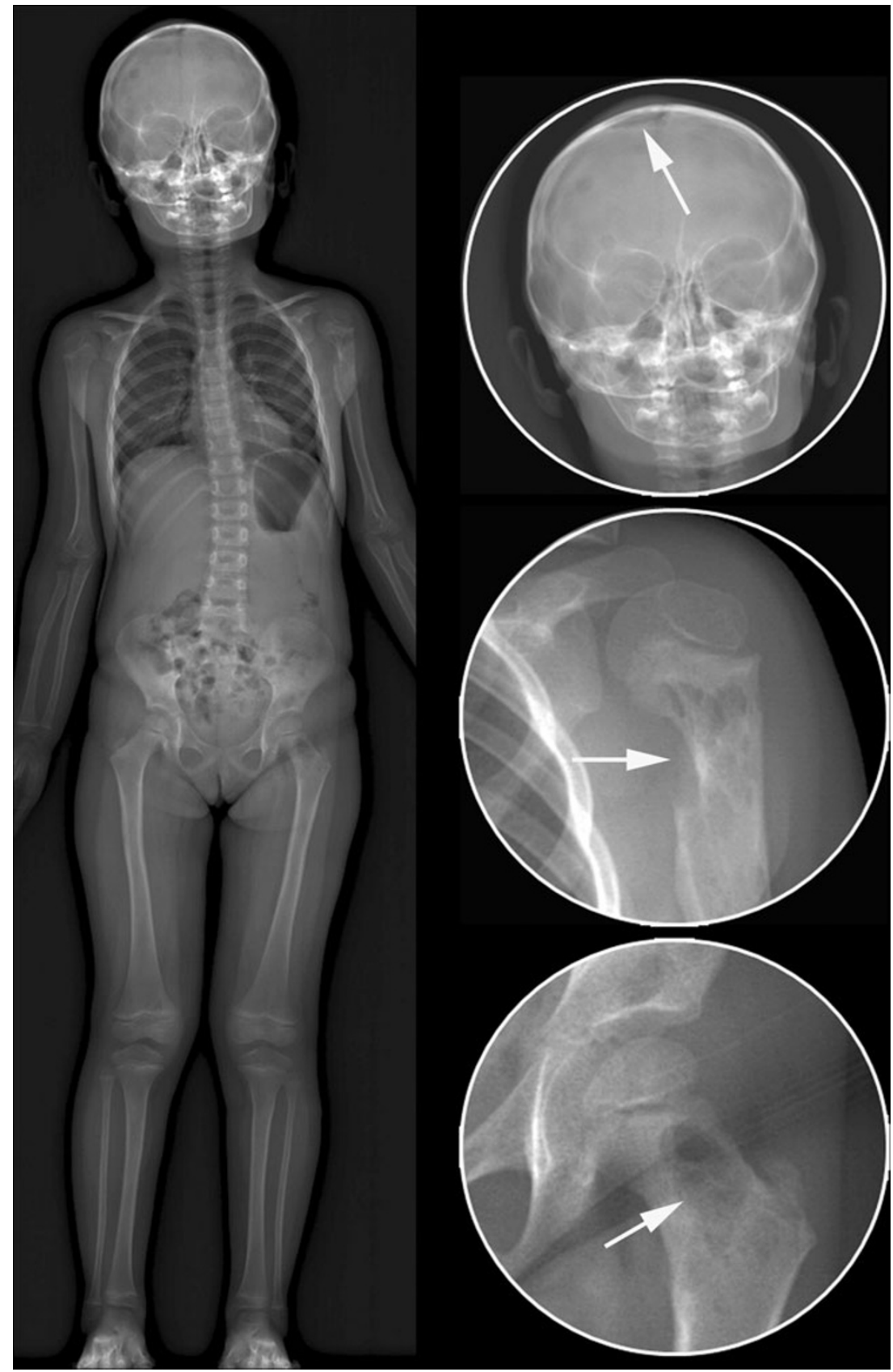


and multisystem disease. Severity of the disease takes into account the involvement or not of risk organs (i.e. the haematological system, the spleen and the liver) and the presence or not of central nervous system risk lesions (i.e. skull bone lesions with the exception of the vault) [7]. Therefore, different therapeutic approaches may be applied; they include conservative management, local therapy (curettage, excision, intralesional corticosteroid injection, lowdose radiation therapy) and systemic therapy (chemotherapy, corticosteroids, stem cell transplantation) $[4,7]$.

\section{Imaging techniques in assessment of skeletal involvement}

Bone is the most frequently affected tissue in children with $\mathrm{LCH}$, encountered in about $75-80 \%$ of patients with $\mathrm{LCH}[2$, 7], with unifocal involvement being more common than multifocal involvement $[4,8,9]$. LCH can involve any bone, but there is a predilection for the axial skeleton, with more than $50 \%$ of bone lesions occurring in the flat bones (skull, ribs, pelvis) [3]. In the long bones, the femur is the most commonly affected, followed by the humerus and the tibia [3]. Imaging is based predominantly on radiography. In children with biopsy-proven $\mathrm{LCH}$, a chest radiograph and complete skeletal survey have to be obtained for diagnosis and assessment of disease extent, in addition to laboratory evaluation [6]. In our institution, this survey is performed with a low-dose biplanar system whenever possible, because this new technique allows a quick assessment of the axial

a

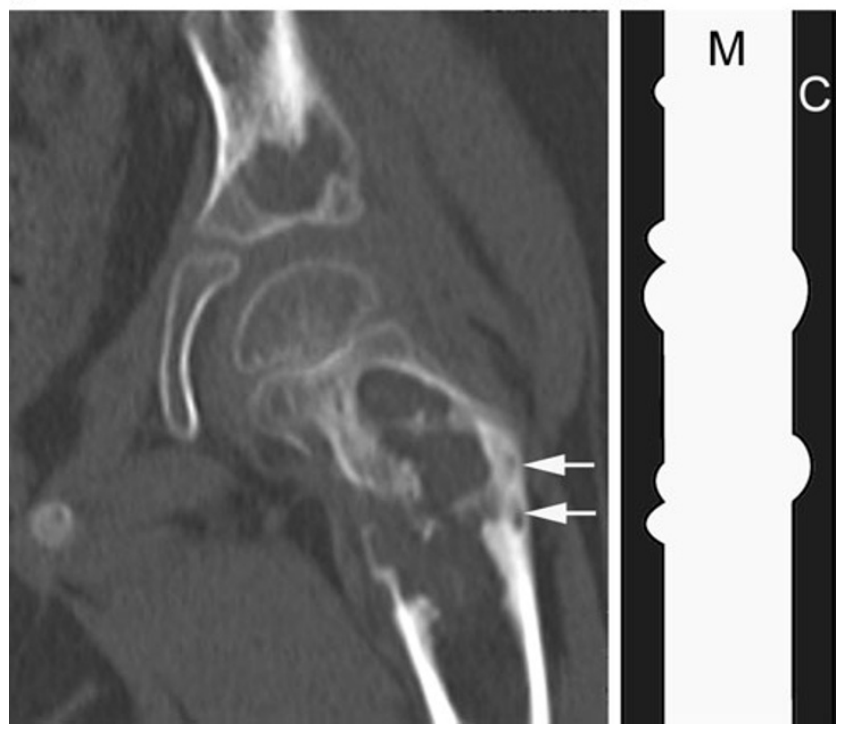

Fig. 2 a Coronal CT image of the left hip shows large, well-defined, lytic, femoral and acetabular lesions. The femoral lesion, at risk of impending fracture, was immobilised thereafter. Note the "budding appearance" of bone destruction (arrows) related to endosteal scalloping. b The diagram depicts this "budding appearance" in the diaphysis of a long bone. $M$ medullary canal, $C$ cortex skeleton in the standing position (Fig. 1) with a reduced amount of radiation exposure (by a factor of 8-10) compared with conventional radiography [10-13]. However, this technique cannot be used in very young children unable to stand and its value has not been assessed yet in LCH. Whatever the technique used, the sensitivity of radiography is limited because lytic lesions become apparent only when 30-50\% of the bone mineral density is already lost and because some areas such as the skull base, the scapulae, the spine and the pelvis may be difficult to assess owing to superposition of bones or bowel gas. Despite this, radiography remains the "gold standard" of the diagnostic and staging procedure. Once a bone lesion is diagnosed, computed tomography (CT) or magnetic resonance imaging (MRI) may be necessary to assess precisely the degree of trabecular and cortical bone destruction in areas at risk of impending fracture (Fig. 2) and to guide a bone biopsy if necessary (CT), or to

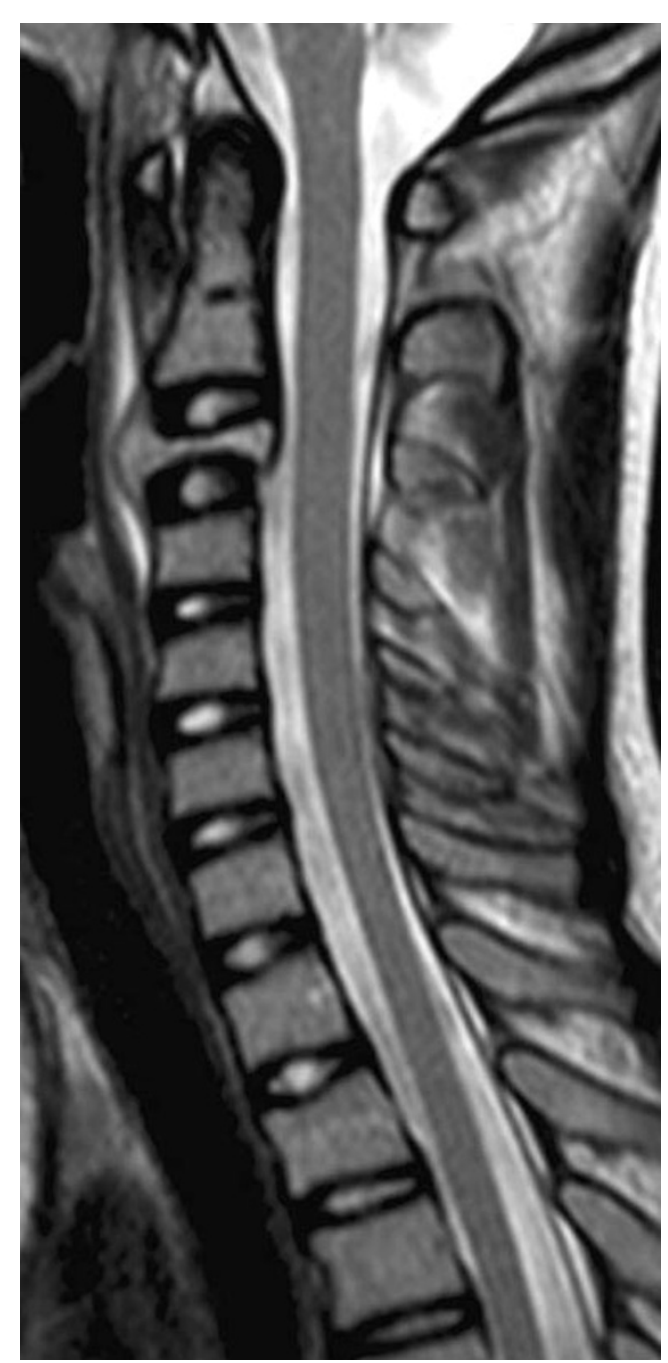

Fig. 3 Sagittal T2-weighted MR image of the cervical spine demonstrates a lesion of $\mathrm{C} 3$ associated with severe vertebral collapse and prevertebral and epidural soft tissue extension. There is no compression of the spinal cord 


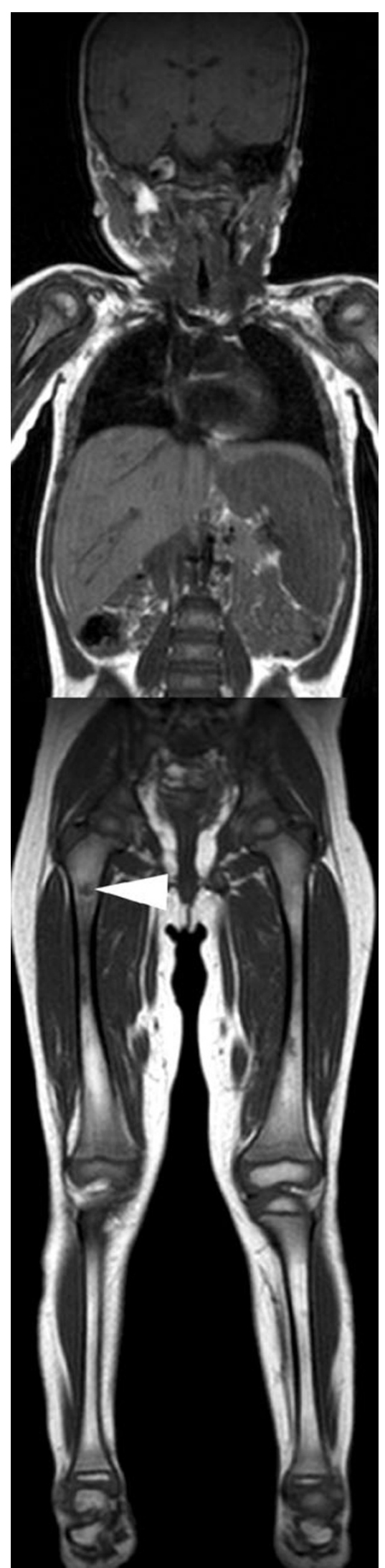

Fig. 4 Coronal whole-body T1-weighted MR image reveals a right femoral bone lesion (arrowhead) and splenomegaly. Courtesy of Pr Guy Sebag and Dr Marianne Alison, Paris, France assess the degree of soft tissue infiltration in areas at risk of neurological complications (MRI) (Fig. 3). Bone scintigraphy may be a complementary technique to the radiographic skeletal survey in assessment of bone involvement, but its sensitivity is limited as well, especially in the skull $[14,15]$, and this modality has radiation issues. Recently, new imaging techniques, such as positron emission tomographycomputed tomography (PET-CT) and whole-body MRI, have developed in view of an improved assessment of the extent and severity of the disease [16-18]. Positron emission tomography-computed tomography (PET-CT) provides information related to disease activity and response to therapy $[17,18]$, but the inherent radiation burden is questionable. Whole-body MRI can detect extra-skeletal and skeletal lesions without use of ionising radiation (Fig. 4) [12], but its exact role in the diagnostic algorithm of $\mathrm{LCH}$ needs further investigation and access to this technique is still limited.

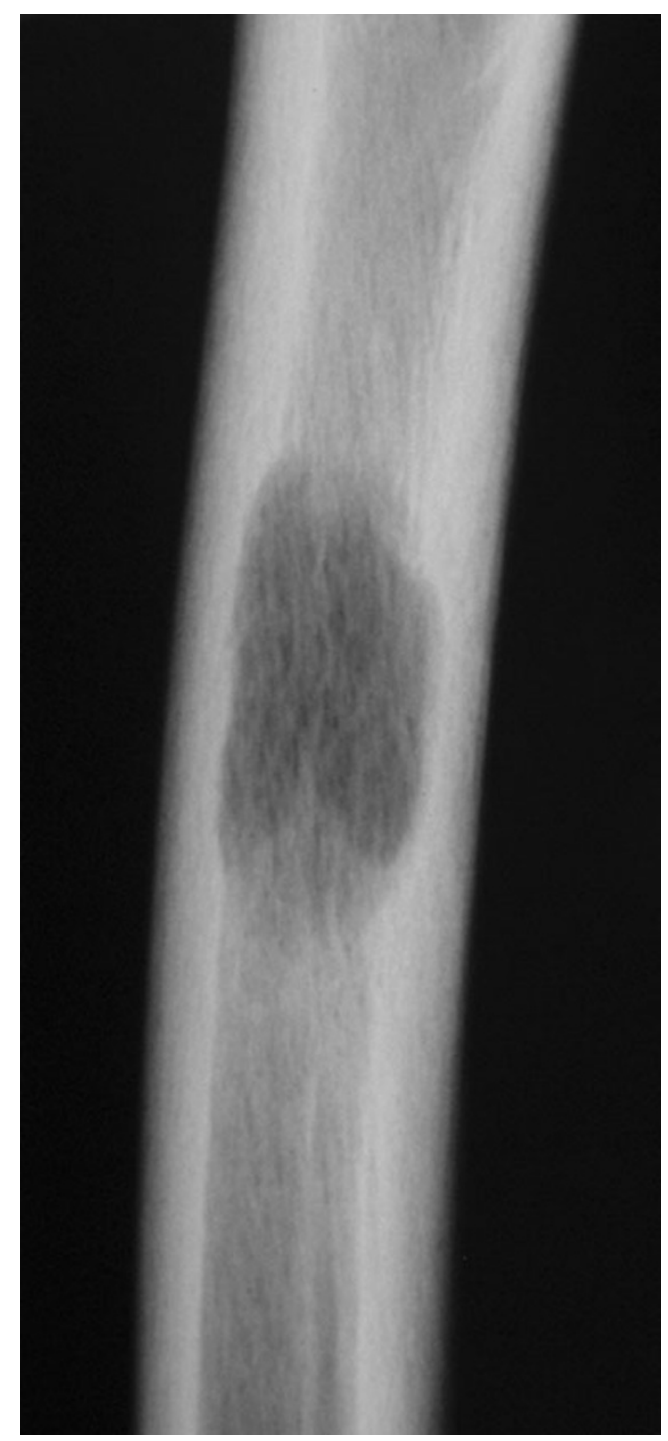

Fig. 5 Anteroposterior radiograph of a femur shows an ill-defined lytic medullary lesion 


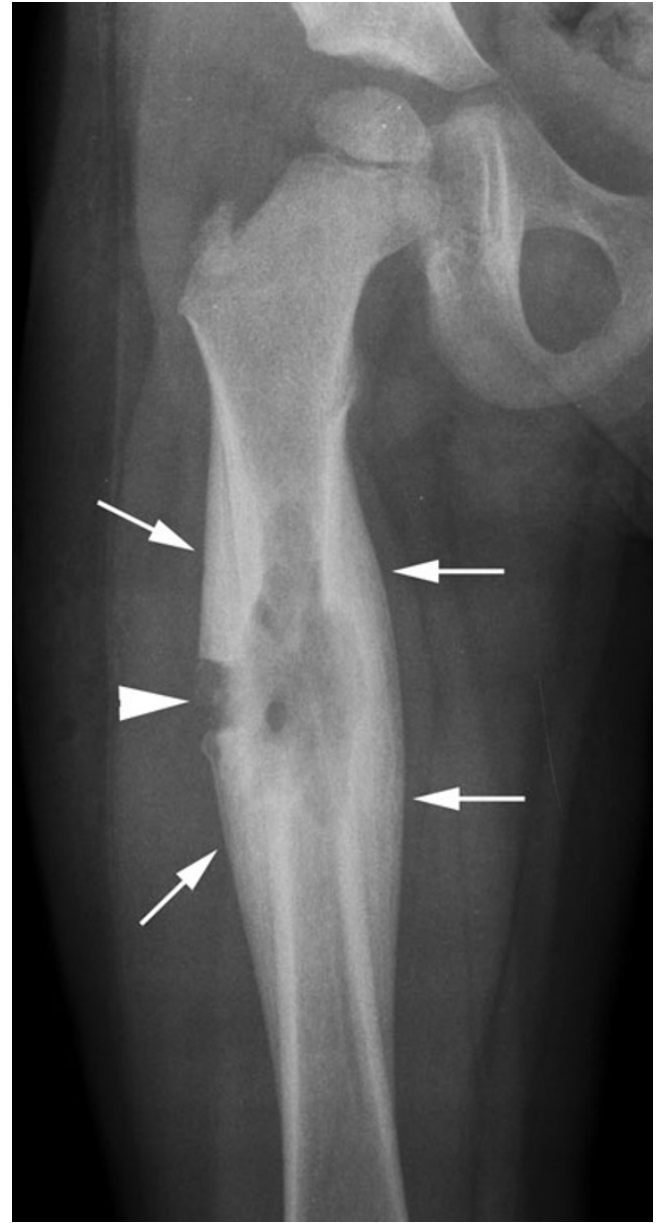

Fig. 6 Anteroposterior radiograph of the right femur reveals ill-defined trabecular osteolysis associated with periosteal buttressing (arrows), indicating a relatively slow-growing lesion. A bone biopsy (arrowhead) confirmed the diagnosis

\section{a}

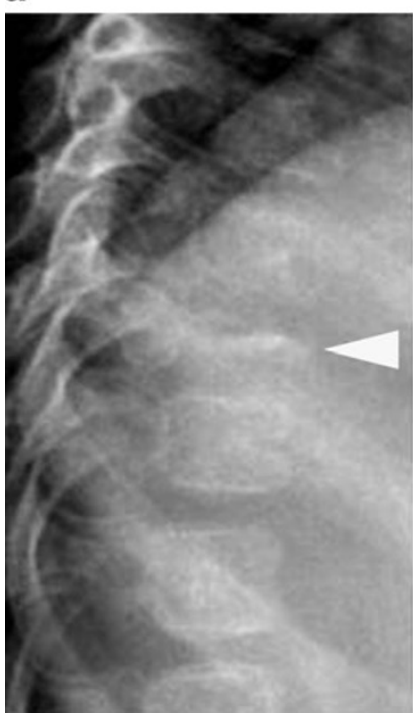

\section{b}

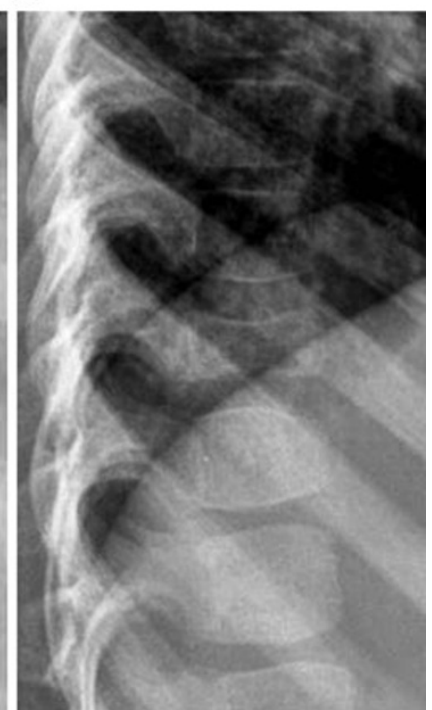

Fig. 7 a Lateral radiographs of the spine show a complete vertebral collapse of T10 (vertebra plana appearance) (arrowhead) with preservation of the adjacent disc spaces. b Partial height restitution is seen 1 year later

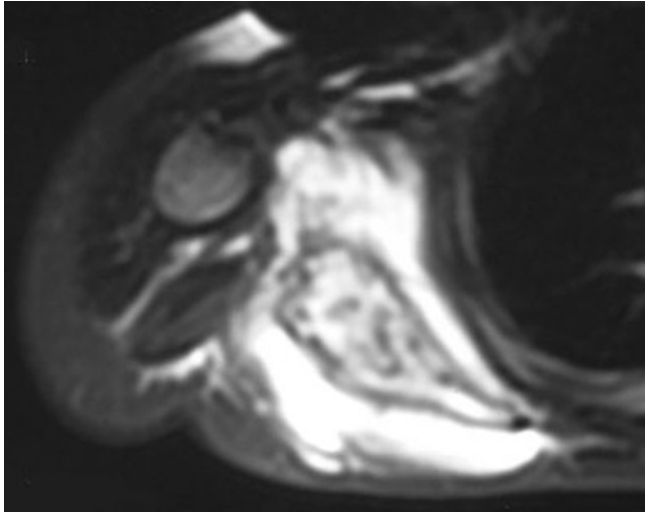

Fig. 8 Axial T2-weighted MR image reveals extensive signal intensity changes within the bone marrow of the right scapula and the adjacent soft tissues. The lesion is markedly expansile

Therefore, radiography still remains the screening technique of choice for the evaluation of children with suspected LCH.

\section{Imaging features of skeletal involvement}

The radiographic appearance of the lesions depends on the site of involvement and the phase of the disease. The axial skeleton (skull, spine, scapula, and pelvis) and the long bones are more commonly affected. Bone involvement usually presents as a single or multiple osteolytic lesions, round or oval-shaped. Their border can appear either well or poorly defined (Fig. 5). Such an osseous involvement is very similar to that of multiple myeloma in adults. In $\mathrm{LCH}$, however, periosteal reaction may be associated with osseous lesions. When present, periostitis demonstrates the appearance of a single layer of periosteal bone or a more suggestive buttressed pattern (Fig. 6). During the healing phase, sclerotic margins appear but sclerosis is usually limited. Lesions can eventually completely disappear, with no or little deformity

a

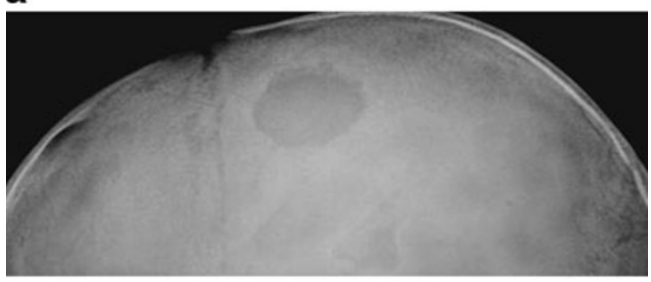

b

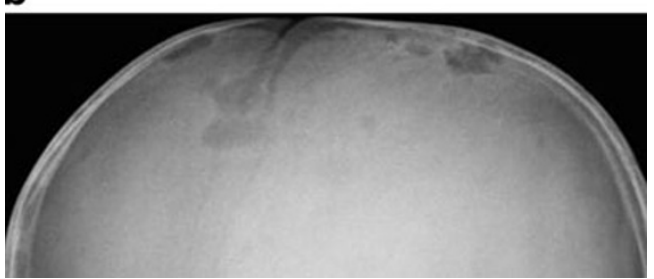

Fig. 9 Lateral skull radiographs demonstrate one (a) or several (b) well-defined lytic lesions of the skull in the frontal and parietal bones 

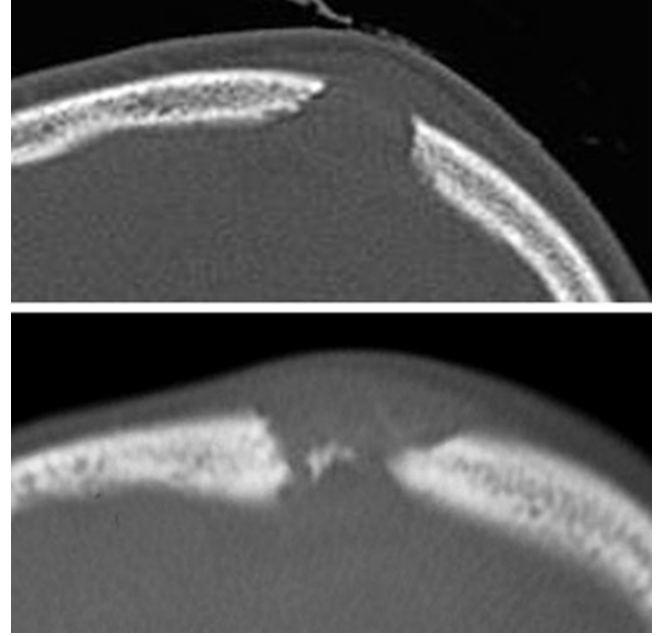

Fig. 10 Axial CT scans of two calvarial lesions show bevelled margins due to unequal destruction of the inner and outer tables of the skull and a "button" sequestrum (i.e. a fragment of residual bone within a lytic lesion)

(Fig. 7) [3]. CT and MR features are non-specific but an extensive bone marrow oedema is usually seen around bone lesions on MRI (Fig. 8).

\section{Skull}

Calvarium This is affected more often than the skull base, and lesions occur especially in the parietal or the frontal region [19]. Radiographically, they typically appear as one or multiple well-defined punched-out osteolytic lesions (Fig. 9). Unequal involvement of the inner and outer tables

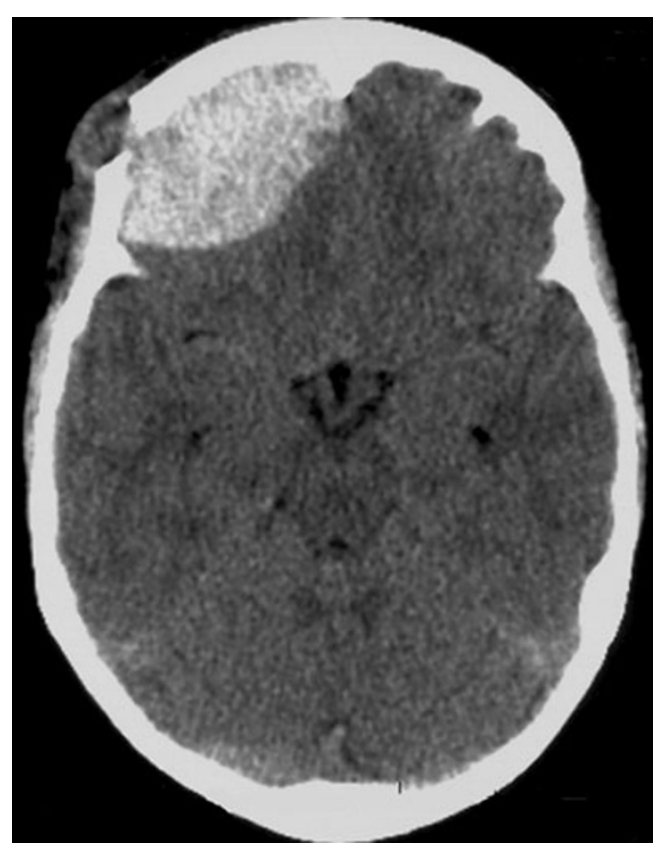

Fig. 11 Axial unenhanced CT scan exhibits an extra-dural hematoma related to the bleeding of a right frontal bone lesion

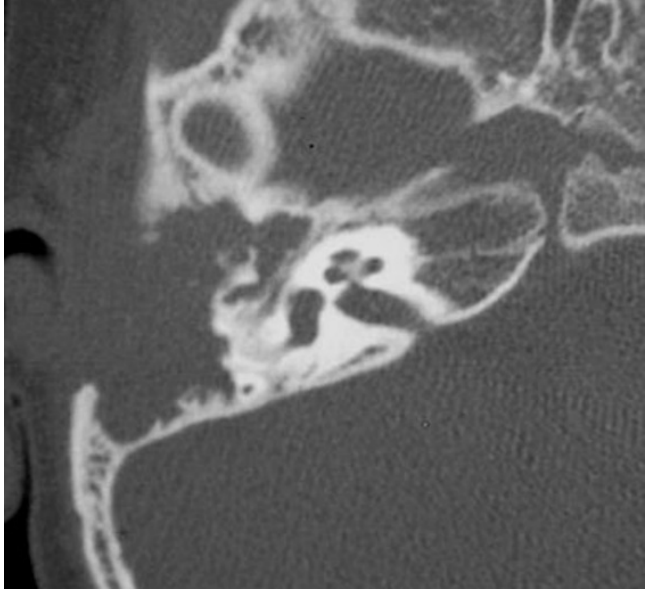

Fig. 12 Axial CT scan of the right mastoid in a child presenting with otorrhea demonstrates an important destruction of the mastoid part of the right temporal bone and the middle ear, with partial lysis of the ossicular chain. Complete reossification of the temporal bone was seen on $\mathrm{CT} 2$ years later

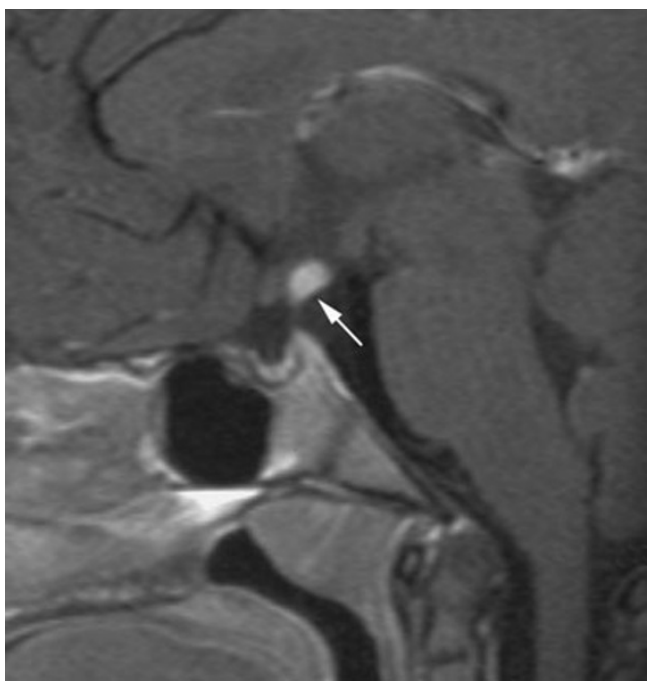

Fig. 13 Sagittal fat-suppressed enhanced T1-weighted MR image shows nodular enhancement of the infundibular pituitary stalk (arrow)

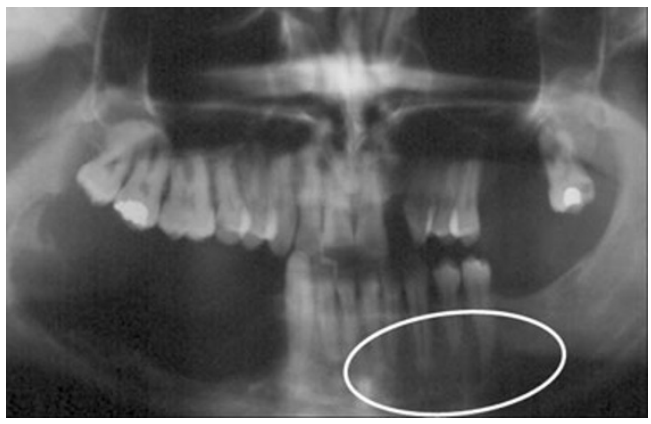

Fig. 14 Dental panoramic radiograph in a young adult shows a left mandibular lesion. The destruction of the alveolar bone gives the appearance of "floating teeth" 


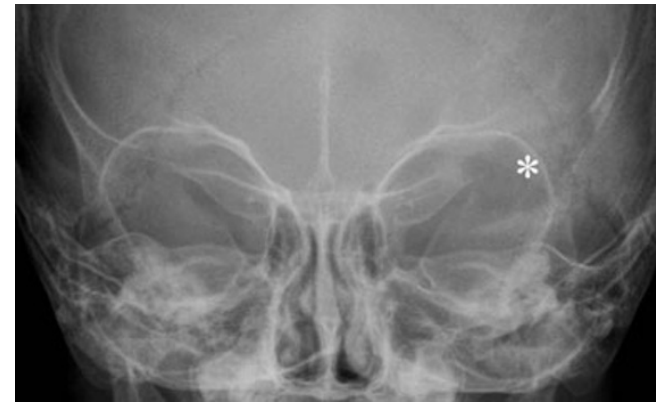

Fig. 15 Anteroposterior radiograph of the skull shows osteolysis of the lateral part of the left orbit (asterisk)

may give the lesions a characteristic bevelled-edge appearance on CT scans (Fig. 10). These lytic lesions may sometimes contain a fragment of intact bone, referred to as "button sequestrum" (Fig. 10). This sign, however, is not specific for $\mathrm{LCH}$ and can also be seen in other diseases such as osteomyelitis [20]. Multiple lesions may enlarge and coalesce, giving a "geographic" appearance to the skull vault. On MRI, calvarial lesions usually appear isointense at T1weighted imaging, heterogeneously hyperintense at T2weighted imaging, and present a marked enhancement after gadolinium injection. An associated soft-tissue mass or reactive dural enhancement can also be well evaluated on MRI [21]. In extremely rare cases, bleeding of LCH lesions may be responsible for an extradural haematoma (Fig. 11) [22]. The main differential diagnoses of calvarial lytic lesions on imaging include epidermoid and dermoid cysts for a solitary lesion and metastatic neuroblastoma for multiple lesions. Dermoid and epidermoid cysts are most commonly seen in midline locations, sometimes associated with a sinus tract; CT attenuation and MR signal intensity changes vary depending on cyst's content (fat in dermoid cysts, fluid in epidermoid cysts) [23]. Skull vault metastases do not have well-defined bevelled edges, like in $\mathrm{LCH}$, and may be associated with speculated ("hair-on-end") periosteal reaction.

Skull base The temporal bone is the most commonly affected part of the skull base. CT shows destructive bone lesions

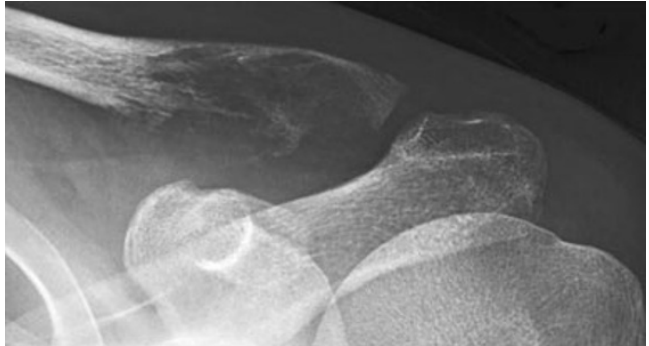

Fig. 17 Anteroposterior radiograph of the left clavicle in a young adult shows an ill-defined, slightly expansile, lytic lesion of the lateral part of the bone

with associated soft-tissue masses involving the mastoid (Fig. 12), with the squamous portion and middle ear less affected [24, 25]. Involvement of the auditory ossicles and the internal ear is not very frequent despite the extensive bony destruction. Paralysis of the cranial nerves is also unusual, but can occur when the petrous apex is involved or when there is an extension to the central nervous system. The main differential diagnosis of temporal bone involvement on imaging is mastoiditis, but infection is usually not associated with extensive osseous destruction and contrast-enhanced CT or MR images may reveal an accompanying abscess. While recovering, the $\mathrm{LCH}$ lesions show early disappearance of the soft-tissue mass, followed by reossification and remodelling of the involved bone [25]. A less commonly affected area in the skull base is the sphenoid bone with involvement of the clivus, the sphenoid wings or the pituitary stalk. The latter may be involved isolatedly (Fig. 13) or in association with sphenoid bone involvement.

Mandible and maxilla Panoramic radiographs may show severe alveolar bone destruction, which produces the appearance of "floating teeth" (Fig. 14) [26].

Orbit This is another site of predilection for LCH that usually presents as an isolated bone lesion with an associated soft tissue mass, although it can also be encountered in multifocal or multisystemic disease. It occurs predominantly in the superior or superolateral orbital region (Fig. 15) [24,
Fig. 16 a Chest radiograph reveals an expansile and lytic lesion of the lateral portion of a left rib (arrowhead). 16b Axial fat-suppressed T2-weighted MR image and sagittal fat-suppressed gadolinium-enhanced T1weighted MR image show extensive bone marrow changes with soft tissue extension creating an extrapleural mass

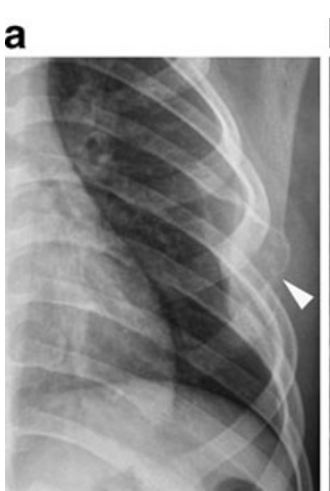

b

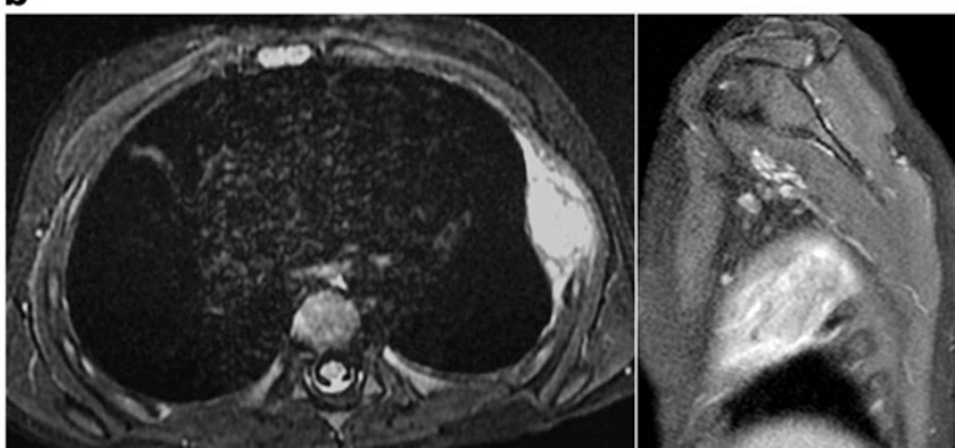




\section{a}

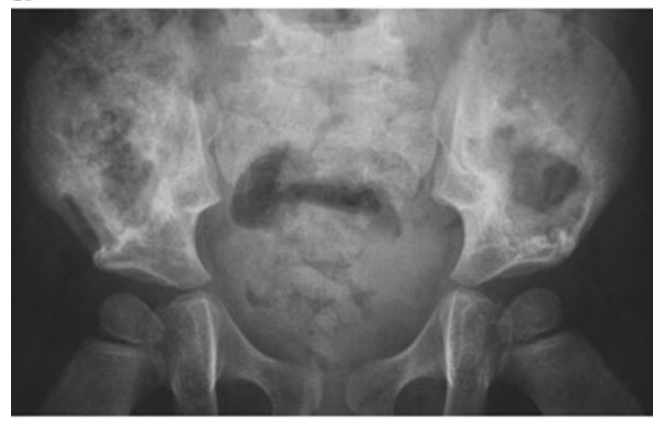

b

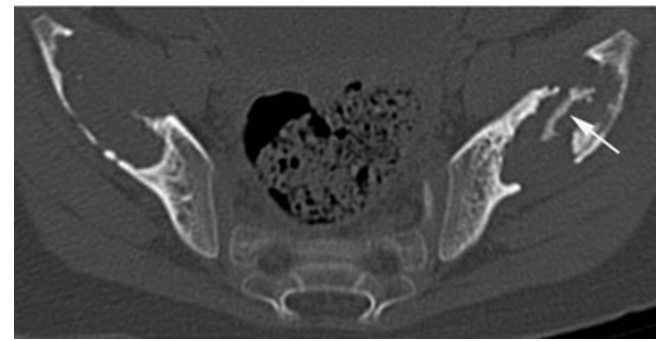

Fig. 18 a Anteroposterior radiograph of the pelvis reveals bilateral lytic lesions of the iliac wings. On the left, well-defined sclerotic margins are seen around the lesion that extends to the supra-acetabular region. b On axial CT scan, note the presence of a fragment of intact bone within the left bone lesion (arrow) with reactive sclerosis

27]. Complementary CT and/or MRI are useful to precisely determine the destruction of osseous structures and the extension into the orbit, and possibly the temporal fossa, forehead, and face [24].

\section{Chest wall}

Rib lesions are lytic (Fig. 16), sometimes associated with a pathological fracture. An extrapleural mass may result from soft-tissue extension [3]. Some rib lesions may be expansile (Fig. 16) or may appear aggressive, with a large soft tissue mass that may be mistaken in some cases for Ewing's sarcoma. a

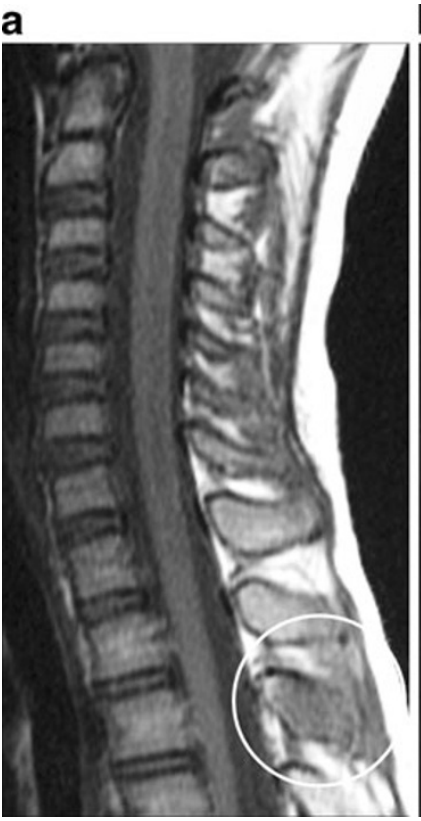

b

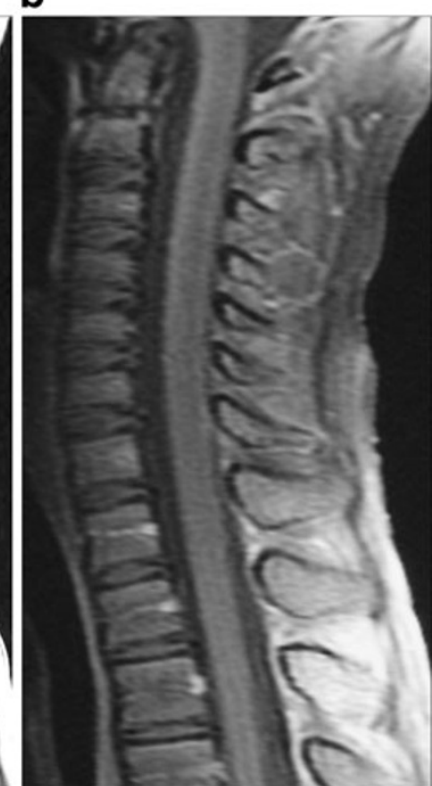

Fig. 20 Sagittal unenhanced T1- (a) and fat-suppressed gadoliniumenhanced T1-weighted (b) MR images reveal an involvement limited to the posterior elements

However, even if a bone biopsy is mandatory, the presence of extensive signal intensity changes around the lesion (Fig. 16) is more suggestive of LCH than Ewing's sarcoma. The clavicle is less frequently involved in children but some cases of clavicular location have been reported in young adults (Fig. 17) [28, 29]. In contrast, scapular lesions are not uncommon in children and may appear expansile (Fig. 8) and/or aggressive.

\section{Pelvis and spine}

Pelvis The iliac wings and the supra-acetabular region are more frequently involved. In the pelvis, bone lesions are not always purely lytic and may exhibit well-defined sclerotic margins (Fig. 18) [3].
Fig. 19 a Axial CT scan demonstrates an ill-defined osteolysis of a thoracic vertebra involving the vertebral body but also the right pedicle and the transverse process. b Sagittal fatsuppressed gadoliniumenhanced T1-weighted MR image shows the degree of epidural extension. The collapsed vertebral body is evident

\section{a}

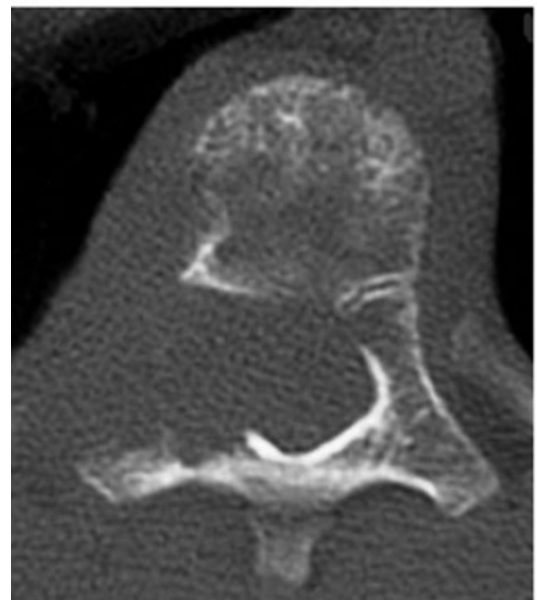

b

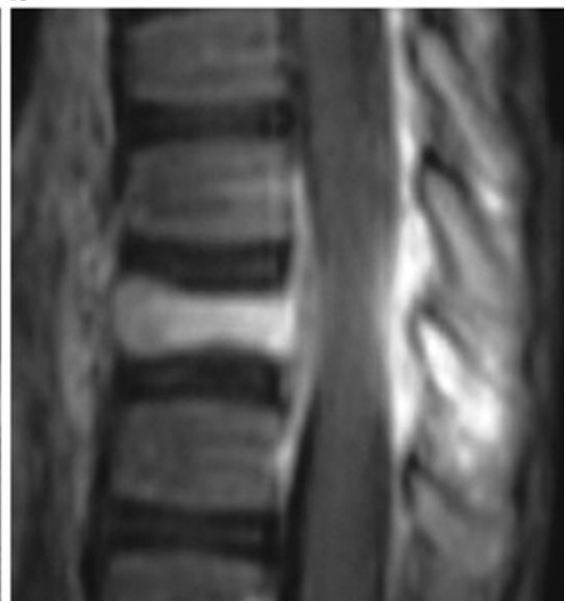




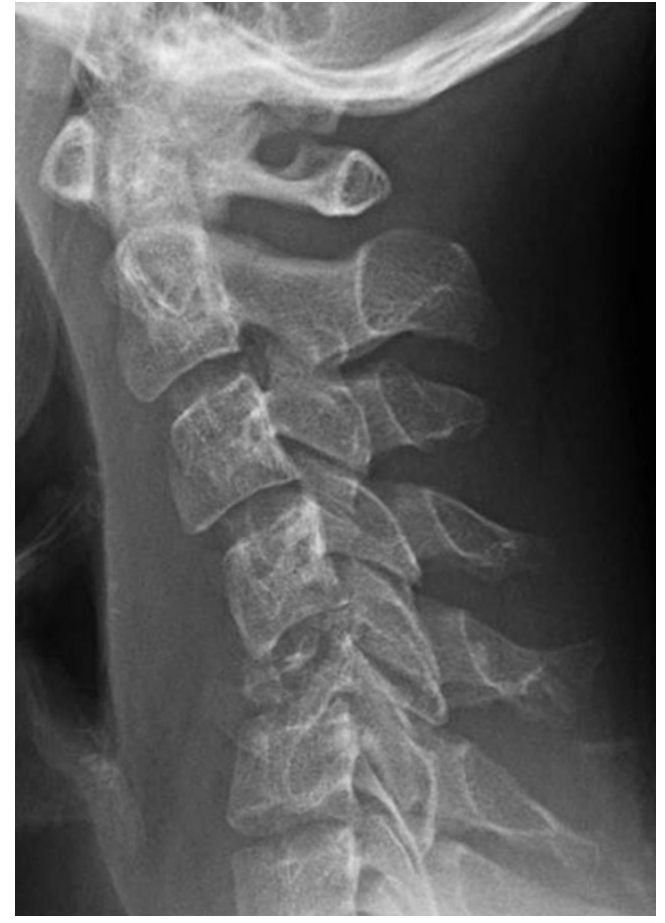

Fig. 21 Lateral radiograph shows marked destruction of C5 body responsible for cervical kyphosis

Spine In the spine, $\mathrm{LCH}$ has a predilection for the thoracic spine, followed by the lumbar spine and the cervical spine. In most cases, it involves the vertebral bodies with relative sparing of the posterior elements. Such involvement may result in anterior wedging or more commonly, in complete collapse with a characteristic vertebra plana appearance (Fig. 7) [9, 30]. With healing, partial (Fig. 7) or almost complete height restitution of the involved vertebra may be seen $[3,9]$. In some patients, asymmetrical vertebral body collapse, involvement of the vertebral body as well as the posterior elements (Fig. 19), and much less frequently, lesions limited to the posterior element may be encountered (Fig. 20) [3]. Solitary lytic lesions in the cervical spine are very rare; they may be associated with spinal deformity a
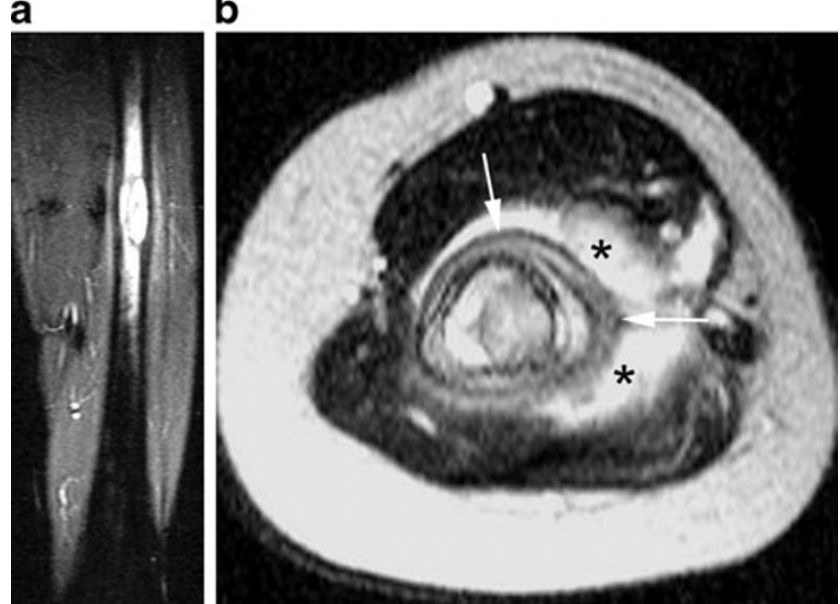

Fig. 23 a Coronal fat-suppressed T2-weighted MR image reveals focal bone marrow replacement within the femoral diaphysis with a "budding" appearance due to endosteal scalloping and extensive oedema within the bone marrow and the adjacent soft tissues. b Axial T2weighted MR image in another patient shows circumferential periosteal reaction (arrows) and extensive bone marrow oedema within the bone marrow and the adjacent soft tissues (asterisks)

(Fig. 21) or epidural soft-tissue extension that is welldepicted on MRI (Fig. 3). However, spinal cord compression is extremely rare [31].

\section{Long bones}

In the long bones, LCH initially presents as ill-defined areas of trabecular and/or cortical bone destruction, usually involving the diaphysis (Fig. 5), the metaphysis or both. When a lesion involves the metaphysis, it does not usually cross the growth plate (Fig. 22). Thickening of the cortical bone and periosteal reaction (Fig. 6) may be associated. Lesions may later become well defined, and sclerotic margins may appear. Endosteal scalloping responsible for a "budding appearance" on CT and MRI (Figs. 2 and 23) [28], as well as extensive signal intensity changes within the bone marrow (Fig. 23), the periosteum and the adjacent soft tissues, may be helpful
Fig. 22 a Coronal CT scan (22a) demonstrates an osteolytic lesion in the metaphysis of the right femur, without involvement of the epiphysis. Note the persistence of tiny bone fragments within the lesion. $\mathbf{b}$ Coronal unenhanced T1- and (c) fat-suppressed gadoliniumenhanced T1-weighted MR images show non-specific but extensive signal intensity changes within the bone marrow and the adjacent soft tissues as well as reactive synovitis

\section{a}

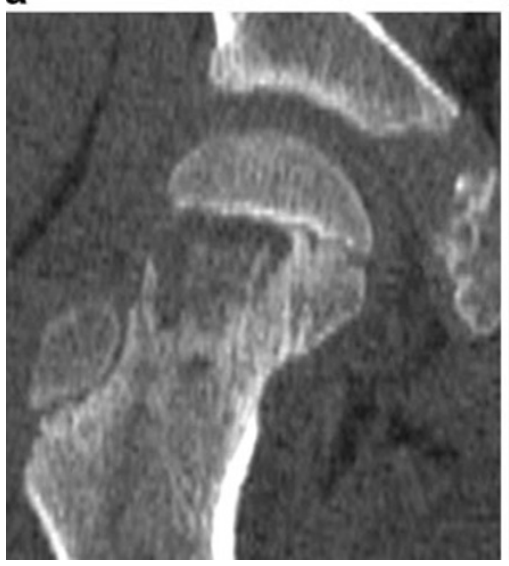

b

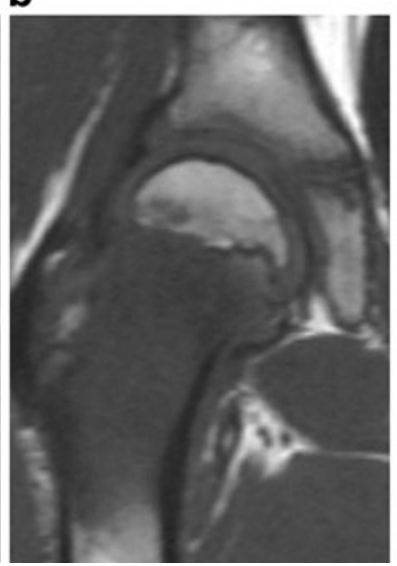

C

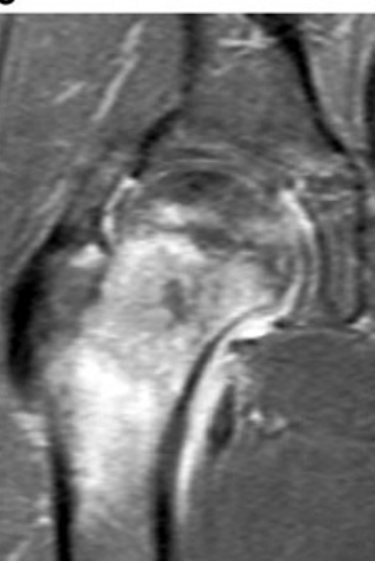


signs for the diagnosis of $\mathrm{LCH}$. Involvement of the epiphysis is rare; a solitary epiphyseal lesion should thus suggest differential diagnoses such as chondroblastoma or epiphyseal osteomyelitis [19]. Transphyseal extension of LCH is also unusual and may result in premature closing of the physis. Other unusual features of LCH have been reported such as isolated cortical lesions, soft-tissue calcifications, extraskeletal soft tissue masses, fluid-fluid levels, and involvement of the short tubular bones of hands and feet [19].

\section{Conclusion}

LCH is a rare disorder, mostly affecting children. Osseous involvement in children with LCH is very similar to that seen in adults with multiple myeloma (i.e. predominance of destructive lesions in axial skeleton). It is best assessed with conventional or digital skeletal surveys. Radiographic features are variable, from a suggestive appearance to a more aggressive one, which may mimic Ewing's sarcoma or osteomyelitis. Radiography may be complemented by CT and/or MRI to delineate the extent of osseous destruction or the extent of bone marrow and soft tissue involvement respectively. MR findings are non-specific, but extensive bone marrow changes and/or a "budding appearance" of bone lesions may be suggestive of the diagnosis. Biopsy is necessary to obtain diagnosis confirmation.

\section{Conflicts of interest None.}

Open Access This article is distributed under the terms of the Creative Commons Attribution License which permits any use, distribution, and reproduction in any medium, provided the original author(s) and the source are credited.

\section{References}

1. Windebank K, Nanduri V (2009) Langerhans cell histiocytosis. Arch Dis Child 94:904-908

2. Guyot-Goubin A, Donadieu J, Barkaoui M, Bellec S, Thomas C, Clavel J (2008) Descriptive epidemiology of childhood Langerhans cell histiocytosis in France, 2000-2004. Pediatr Blood Cancer 51:71-75

3. Stull MA, Kransdorf MJ, Devaney KO (1992) Langerhans cell histiocytosis of bone. Radiographics 12:801-823

4. Weitzman S, Egeler RM (2008) Langerhans cell histiocytosis: update for the pediatrician. Current Opin Pediatr 20:23-29

5. Leonidas JC, Guelfguat M, Valderrama E. Langerhans' cell histiocytosis (203) Lancet 361:1293-1295

6. Satter EK, High WA (2008) Langerhans cell histiocytosis: a review of the current recommendations of the Histiocyte Society. Pediatr Dermatol 25(29):1-295

7. Haupt R, Minkov M, Astigarraga I, Schäfer E, Nanduri V, Jubran R, Egeler RM, Janka G, Micic D, Rodriguez-Galindo C, Van Gool S, Visser J, Weitzman S, Donadieu J, Euro Histio Network (2013) Langerhans cell histiocytosis (LCH): guidelines for diagnosis, clinical work-up, and treatment for patients till the age of 18 years. Pediatr Blood Cancer 60:175-184

8. The French Langerhans' Cell Histiocytosis Study Group (1996) A multicentre retrospective survey of Langerhans' cell histiocytosis: 348 cases observed between 1983 and 1993. Arch Dis Child 75:17-24

9. Azouz EM, Saigal G, Rodriguez MM, Podda A (2005) Langerhans' cell histiocytosis: pathology, imaging and treatment of skeletal involvement. Pediatr Radiol 35:103-115

10. Dubousset J, Charpak G, Skalli W, Kalifa G, Lazennec JY (2007) EOS stereo-radiography system: whole-body simultaneous anteroposterior and lateral radiographs with very low radiation dose. Rev Chir Orthop Reparatrice Appar Mot 93:141-143

11. Deschênes S, Charron G, Beaudoin G, Labelle H, Dubois J, Miron MC, Parent S (2010) Diagnostic imaging of spinal deformities: reducing patients radiation dose with a new slot-scanning X-ray imager. Spine 35:989-994

12. McKenna C, Wade R, Faria R, Yang H, Stirk L, Gummerson N, Sculpher M, Woolacott N (2012) EOS 2D/3D X-ray imaging system: a systematic review and economic evaluation. Health Technol Assess 16:1-188

13. Gheno R, Nectoux E, Herbaux B, Baldisserotto M, Glock L, Cotten A, Boutry N (2012) Three-dimensional measurements of the lower extremity in children and adolescents using a LDBX-ray device. Eur Radiol 22:765-771

14. Dogan AS, Conway JJ, Miller JH, Grier D, Bhattathiry MM, Mitchell CS (1996) Detection of bone lesions in Langerhans cell histiocytosis: complementary roles of scintigraphy and conventional radiography. J Pediatr Hematol Oncol 18:51-58

15. Howarth DM, Mullan BP, Wiseman GA, Wenger DE, Forstrom LA, Dunn WL (1996) Bone scintigraphy evaluated in diagnosing and staging Langerhans' cell histiocytosis and related disorders. J Nucl Med 37:1456-1460

16. Goo HW, Yang DH, Ra YS, Song JS, Im HJ, Seo JJ, Ghim T, Moon HN (2006) Whole-body MRI of Langerhans cell histiocytosis: comparison with radiography and bone scintigraphy. Pediatr Radiol 36:1019-1031

17. Binkovitz LA, Olshefski RS, Adler BH (2003) Coincidence FDGPET in the evaluation of Langerhans' cell histiocytosis: preliminary findings. Pediatr Radiol 33:598-602

18. Kaste SC, Rodriguez-Galindo C, McCarville ME, Shulkin BL (2007) PET-CT in pediatric Langerhans cell histiocytosis. Pediatr Radiol 37:615-622

19. Hindman BW, Thomas RD, Young LW, Yu L (1998) Langerhans cell histiocytosis: unusual skeletal manifestations observed in thirty-four cases. Skeletal Radiol 27:177-181

20. Krasnokutsky MV (2005) The button sequestrum sign. Radiology 236:1026-1027

21. Okamoto K, Ito J, Furusawa T, Sakai K, Tokiguchi S (1999) Imaging of calvarial eosinophil granuloma. Neuroradiology 41:723728

22. Mut M, Cataltepe O, Bakar B, Cila A, Akalan N (2004) Eosinophilic granuloma of the skull associated with epidural haematoma: a case report and review of the literature. Childs Nerv Syst 20:765769

23. Morón FE, Morriss MC, Jones JJ, Hunter JV ((2004) R) Lumps and bumps on the head in children: use of CT and MR imaging in solving the clinical diagnostic dilemma. Radiographics 24:1655-1674

24. D'Ambrosio N, Soohoo S, Warshall C, Johnson A, Karimi S (2008) Craniofacial and intracranial manifestations of Langerhans cell histiocytosis: report of findings in 100 patients. AJR Am J Roentgenol 191:589-597

25. Fernández-Latorre F, Menor-Serrano F, Alonso-Charterina S, Arenas-Jiménez J (2000) Langerhans' cell histiocytosis of the temporal bone in pediatric patients: imaging and follow-up. AJR Am J Roentgenol 174:217-221 
26. Eckardt A, Schultze A (2003) Maxillofacial manifestations of Langerhans cell histiocytosis: a clinical and therapeutic analysis of 10 patients. Oral Oncol 39:687-694

27. Herwig MC, Wojno T, Zhang Q, Grossniklaus HE (2012) Langerhans cell histiocytosis of the orbit: five clinicopathologic cases and review of the literature. Surv Ophthalmol. doi:10.1016/j.survophthal.2012.09.004

28. Song YS, Lee IS, Yi JH, Cho KH, Kim do K, Song JW (2011) Radiologic findings of adult pelvis and appendicular skeletal Langerhans cell histiocytosis in nine patients. Skeletal Radiol 40:1421-1426
29. Verbist B, Geusens E, Brys P, Verslegers I, Samson I, Sciot R, Baert AL (1998) Langerhans cell histiocytosis of the clavicle: a case report. Eur Radiol 8:1357-1358

30. Yeom JS, Lee CK, Shin HY, Lee CS, Han CS, Chang H (1999) Langerhans' cell histiocytosis of the spine. Analysis of twentythree cases. Spine 24:1740-1749

31. Jang KS, Jung YY, Kim SW (2010) Langerhans cell histiocytosis causing cervical myelopathy in a child. J Korean Neurosurg Soc 47:458-460 